\title{
Química e Física no espaço vazio $^{1}$
}

Ake Hjalmarson ${ }^{2}$

\section{Resumo}

Investigação química de ponta faz-se também, hoje em dia, em observatórios de radio-astronomia, onde são descobertos e interpretados sinais fracos de compostos químicos existentes em longínquas nuvens de gás cósmico. Estas moléculas no espaço vazio não são, no entanto, meras curiosidades químicas. Elas têm revelado a existência de nuvens gigantes de gás interestelar, locais de formação presente e futura de estrelas. As moléculas são os sensores mais importantes das condições e processos físicos que ocorrem bem no interior destas imensas nuvens escuras de gás e poeira e o livre transporte de energia pelas linhas espectrais moleculares permite $o$ arrefecimento nebular necessário d̀ formação de núcleos densos e, em última análise, de estrelas.

\section{O nosso lugar no Universo}

O material bruto que constitui a matéria de hoje formou-se poucos minutos após o "Big Bang", i.e., após a criação do nosso Universo. Esse material "cristalizou" nos elementos mais leves - cerca de $75 \%$ em Hidrogénio e $25 \%$ em Hélio, por massa (Weinberg, 1987). A partir do “Big Bang"' e durante milhð̌es de anos, a matéria foi uniformemente espalhada por todo o Universo e gradualmente foram-se dando condensaçбes na sopa de $\mathrm{H}$, He e fotð̃es (que actualmente podemos observar como a suave radiação cósmica térmica de fundo - 3K). Nestes pré-estádios de galáxias começaram a nascer estrelas brilhantes.

A galáxia que conhecemos melhor é a Via Lactea, na parte exterior da qual se situa a estrela mais próxima de nós - o Sol, rodeado dos seus planetas - que se move com uma velocidade de $250 \mathrm{~km} \mathrm{~s}^{-1}$ numa órbita aproximadamente circular a uma distância de 30000 anos luz ${ }^{3}$ do centro Galáctico. O Sol demora $250 \times 10^{6}$ anos a perfazer uma rotação completa com a Via Láctea e já realizou cerca de 20 rotaçőes desde que nasceu há mais de 5000 milhões de anos. A nossa Galáxia contém aproximadamente $10^{11}$ estrelas. A maior galáxia em espiral semelhante à nossa e que se encontra mais próxima, está situada na constelação de Andrómeda, a uma distância de 2 milhōes de anos luz (Figura 1). No nosso Universo existem cerca de $10^{11}$ galáxias.

\footnotetext{
${ }^{3}$ Um ano luz é a distância que a luz percorre num ano à velocidade de $300000 \mathrm{~km} \mathrm{~s}^{-1}$, i.e., cerca de $10^{13} \mathrm{~km}$. A luz solar geradora de vida demora 8 minutos a alcançar a Terra, cuja distância ao Sol é $150 \times 10^{6} \mathrm{~km}$
}

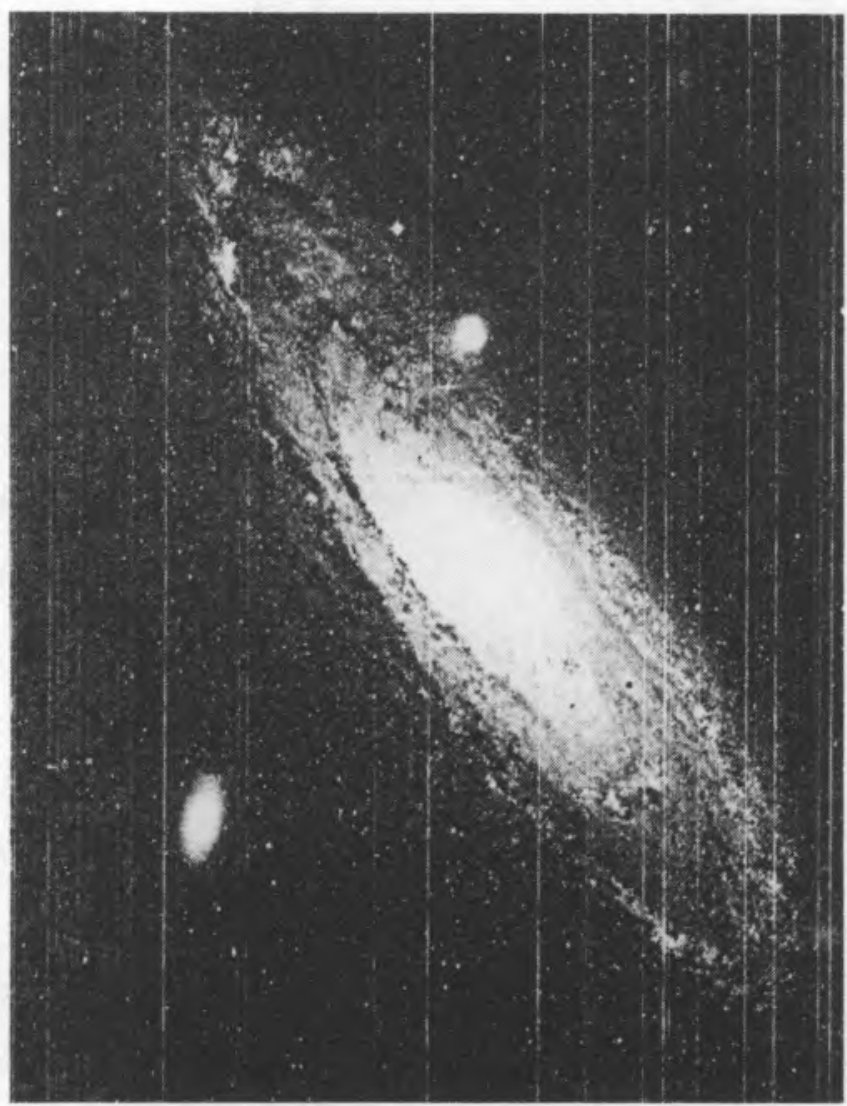

FIGURA I

Galáxia de Andrómeda (M31)

Quando as primeiras estrelas começaram a brilhar nas galáxias, foram buscar a sua energia à fusão dos núcleos de hidrogénio primitivos - como nas bombas de hidrogénio - o que permitiu que hélio e elementos mais pesados (carbono, azoto, oxigénio...) se fossem formando. Surgia assim um grande mecanismo pelo qual estrelas nasciam, consumiam a sua energia e morriam, enquanto o Universo continuava a sua expansão regular. Este Grande Ciclo ainda hoje se processa:

formação de
estrelas $\longrightarrow \begin{aligned} & \text { fusão produzindo energia } \\ & \text { e elementos mais pesados }\end{aligned}$

agonia da morte com expulsão de matéria fundida e poeira para o espaço interestelar

\footnotetext{
1 Tradução de Filomena Martins

${ }^{2}$ Cientista visitante no grupo de Matemática Aplicada da Universidade do Porto.
} 
Por este motivo, podemos-nos considerar todos Filhos das Estrelas. Os átomos da Terra já residiram em várias geraçð̌es de estrelas. O clima que sustenta a vida na Terra é devido aos processos de fusão no Sol. Mesmo a água dos nossos oceanos pode, em grande medida, ter sido aí depositada por cometas que tenham colidido com a Terra. Crê-se que os cometas sejam os restos primitivos da nebulosa protosolar - a nuvem mãe do nosso Sol - cuja água se formoụ em fase gasosa sob condiçð̄es "interestelares" (cf. Figura 2) e posteriormente se condensou em superfícies de grãos de poeira aglomerando-se, em seguida, em direcção ao interior de núcleos cometários formados por blocos sujos de gelo (cf. artigo de Irvine e do número especial da "Nature" sobre o Cometa Halley).

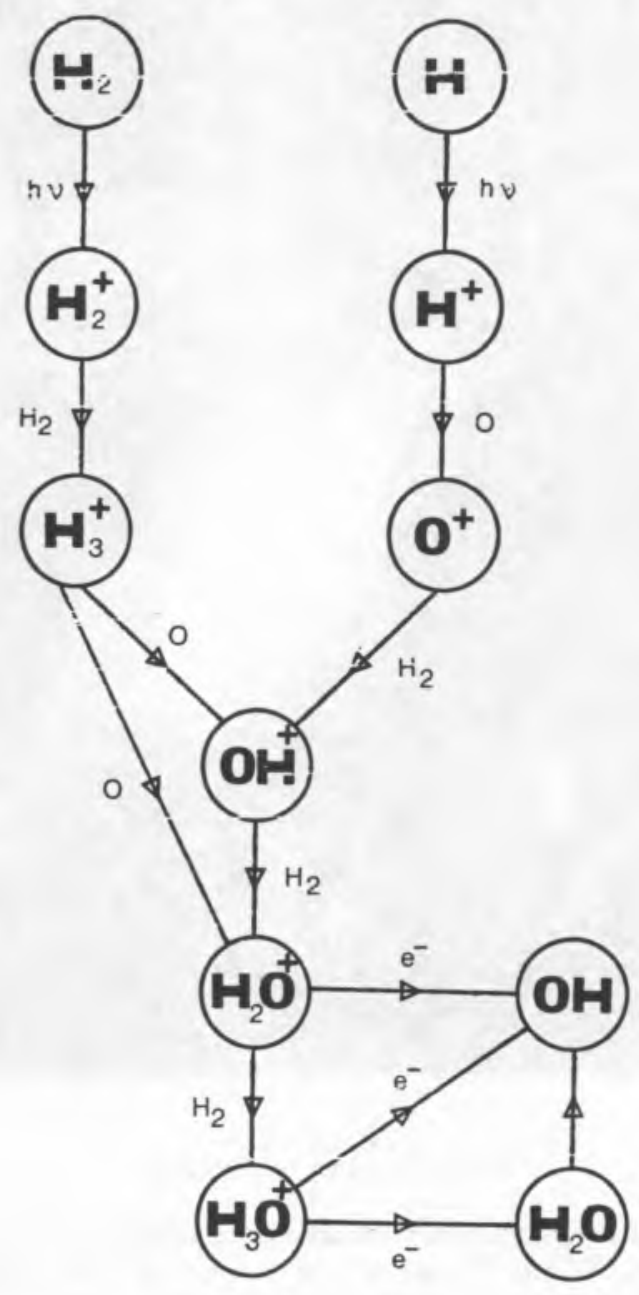

FIGURA 2

Exemplificando a formação eficiente de $\mathrm{H}_{2} \mathrm{O}$ e $\mathrm{OH}$ através de reacçôes ião-molécula. $\mathrm{O} \mathrm{H}_{2}$ e o $\mathrm{H}$ são ionizados por raios cósmicos $e$ também por radiação UV de estrelas recém-nascidas

Espaço interestelar - Um bom vácuo

(Blitz, 1982; Hollenbach e Thronson, 1987; Hjalmarson e Friberg, 1988)

Numa galáxia vulgar como a nossa, a maior parte da matéria $(>90 \%)$ está concentrada no interior das estrelas. ${ }^{4}$. A distância até à estrela mais próxima de nós, a $\alpha$-Centauro, é de 4 anos luz. No vasto espaço

4 "Despreza-se" aqui a, sobejamente debatida, possível massa aureolar da matéria escura e invisível, indicada pela rotação galáctica a grande distância. vazio entre as estrelas encontra-se menos de $10 \%$ de matéria. Aí, a densidade média é de apenas um átomo de $\mathrm{H}$ por $\mathrm{cm}^{3}$ ou $10^{-24} \mathrm{~g}_{\text {por }} \mathrm{cm}^{3}$. Cerca de $99 \%$ dessa matéria é $\mathrm{H}$ (e $\mathrm{He})$ gasoso, e apenas $1 \%$ da massa existe na forma de partículas de poeira microscópicas. $\mathrm{Na}$ atmosfera terrestre a densidade é aproximadamente $10^{19}$ átomos de $\mathrm{H}$ por $\mathrm{cm}^{3}$, donde se conclui que $\mathrm{o}$ espaço interestelar é quase um vácuo perfeito.

O meio interestelar está, no entanto, longe de ser homogéneo. Há nuvens de átomos tão finas que contêm apenas átomos livres, mas há também nuvens de moléculas de elevada densidade onde os átomos reagiram quimicamente (melhor dizendo, "colidiram") para formar moléculas. A densidade destas nuvens de moléculas está compreendida entre 100 e $10^{7} \mathrm{H}_{2}$ por $\mathrm{cm}^{3}$ que ocupam tão só $1 \%$ do volume. A sua massa típica é cerca de $10^{5} \mathrm{M}_{\mathrm{o}}$ (uma massa solar $=\mathrm{M}_{\mathrm{o}}=2 \times 10^{30} \mathrm{~kg}$ ), o que significa que são os corpos mais pesados da galáxia (com excepção, talvez, de um buraco negro no centro da Galáxia). A temperatura nestas nuvens moleculares é, em média, mantida em valores muito baixos $\left(-260{ }^{\circ} \mathrm{C}\right)$ através do eficiente arrefecimento pela radiação molecular.

\section{Moléculas interestelares}

Há 20 anos, conheciam-se apenas três compostos químicos simples que se formavam e sobreviviam no rarefeito gás interestelar, nomeadamente $\mathrm{CN}, \mathrm{CH}$ e $\mathrm{CH}^{+}$, isto é, dois radicais reactivos e um ião molecular. A sua descoberta ocorreu por volta de 1940, a partir das observações da luz de estrelas longínquas a comprimentos de onda específicos identificados por espectroscopia laboratorial.

Através do desenvolvimento de receptores de rádio muito sensíveis - actualmente arrefecidos à temperatura do hélio líquido $\left(-270^{\circ} \mathrm{C}\right)$ para reduzir o ruído do receptor - detectou-se em 1963 o radical $\mathrm{OH}$ e, cinco anos mais tarde, a primeira molécula poliatómica, o $\mathrm{NH}_{3}$. Esta última descoberta não foi apenas encorajadora para os "astroquímicos". Demonstrou directamente a existência de densas nuvens de gás - suficientemente densas e maciças para sustentarem o colapso gravitacional inerente à formação de estrelas. Até aí a nossa compreensão do processo de formação de estrelas carecia da observação da existência de um gás original assaz denso, muito embora James Jeans nos tenha dado há mais de 50 anos um critério matemático elegante para o colapso gravitacional.

No seguimento da deteç̧ão do $\mathrm{NH}_{3}$ em 1968, a descoberta de novas moléculas interestelares ocorreu rapidamente: $\mathrm{H}_{2} \mathrm{O}$ e $\mathrm{H}_{2} \mathrm{CO}$ em 1969; $\mathrm{CO}, \mathrm{CN}, \mathrm{HCN}, \mathrm{HC}_{3} \mathrm{~N}$, $\mathrm{CH}_{3} \mathrm{OH}$ e $\mathrm{HCOOH}$ em $1970 \ldots$ Hoje cerca de 80 moléculas e 50 variantes isotópicas foram já identificadas através de observaçðes de mais de 2000 linhas espectrais no intervalo de comprimentos de onda entre 43 cm e $77 \mu \mathrm{m}$ (Tabela I). A molécula mais pesada até agora identificada é uma cadeia linear de átomos de carbono: $\mathrm{H}-\mathrm{C} \equiv \mathrm{C}-\mathrm{C} \equiv \mathrm{C}-\mathrm{C} \equiv \mathrm{C}-\mathrm{C} \equiv \mathrm{C}-\mathrm{C} \equiv \mathrm{C}-\mathrm{C} \equiv \mathrm{N}$.

\section{Identificação de linhas}

Embora a maior parte das moléculas tenha sido descoberta em pesquisas direccionadas para comprimentos de onda previstos laboratorialmente, cerca de $20 \%$ das espécies da Tabela I foram identificadas "acidentalmente" ou através de inspecçð̋es espectrais ("varrimen- 
tos espectrais"') para grandes domínios de comprimenTabela I - MOLÉCULAS INTERESTELARES

Moléculas simples:

\begin{tabular}{|c|c|c|c|}
\hline $\begin{array}{l}\mathrm{H}_{2} \\
\mathrm{HCl} \ell \\
\mathrm{C}_{2} \\
\mathrm{PN} \\
\mathrm{NaCl} \cdot\end{array}$ & $\begin{array}{l}\mathrm{CO} \\
\mathrm{SiO} \\
\mathrm{HNO} \text { ? } \\
\mathrm{SO}_{2} \\
\mathrm{ACl}^{-}\end{array}$ & $\begin{array}{l}\mathrm{NH}_{3} \\
\mathrm{SiH}_{4} \\
\mathrm{CH}_{4} * \\
\mathrm{H}_{2} \mathrm{O} \\
\mathrm{KCl}\end{array}$ & $\begin{array}{l}\mathrm{CS} \\
\mathrm{SiS} \\
\mathrm{OCS} \\
\mathrm{H}_{2} \mathrm{~S} \\
\mathrm{~A}\end{array}$ \\
\hline
\end{tabular}

Nitrilos, derivados do acetileno e moléculas relacionadas:

\begin{tabular}{|c|c|c|c|}
\hline $\begin{array}{l}\mathrm{HCN} \\
\mathrm{H}_{3} \mathrm{CCN} \\
\mathrm{COCO} \\
\mathrm{COCS} \\
\mathrm{HC}=\mathrm{CH} \cdot \\
\mathrm{H}_{2} \mathrm{C}=\mathrm{CH}_{2}\end{array}$ & $\begin{array}{l}\mathrm{HC}=\mathrm{C}-\mathrm{CN} \\
\mathrm{H}(\mathrm{C}=\mathrm{C})_{2}-\mathrm{CN} \\
\mathrm{H}(\mathrm{C} \equiv \mathrm{C})_{3}-\mathrm{CN} \\
\mathrm{H}(\mathrm{C}=\mathrm{C})_{4}-\mathrm{CN} \\
\mathrm{H}(\mathrm{C}=\mathrm{C})_{3}-\mathrm{CN}\end{array}$ & $\begin{array}{l}\mathrm{H}_{3} \mathrm{C}-\mathrm{C}=\mathrm{C}-\mathrm{CN} \\
\mathrm{H}_{3} \mathrm{C}-\mathrm{C}=\mathrm{C}-\mathrm{H} \\
\mathrm{H}_{3} \mathrm{C}-(\mathrm{C}=\mathrm{C})_{2}-\mathrm{H} \\
\mathrm{H}_{3} \mathrm{C}-(\mathrm{C}=\mathrm{C})_{2}-\mathrm{CN} \\
\mathrm{H}_{3} \mathrm{CNC} \text { ? }\end{array}$ & $\begin{array}{l}\mathrm{H}_{3} \mathrm{C}-\mathrm{CH}_{2}-\mathrm{CN} \\
\mathrm{H}_{2} \mathrm{C}-\mathrm{CH}-\mathrm{CN} \\
\mathrm{HNC} \\
\mathrm{HNCO} \\
\mathrm{HNCS}\end{array}$ \\
\hline \multicolumn{4}{|c|}{ Aldeídos, alcoóis, éteres, cetonas, amidas e moléculas relacionadas: } \\
\hline $\begin{array}{l}\mathrm{H}_{2} \mathrm{C}=\mathrm{O} \\
\mathrm{H}_{2} \mathrm{C}=\mathrm{S} \\
\mathrm{H}_{3} \mathrm{C}-\mathrm{CH}=\mathrm{O} \\
\mathrm{NH}_{2}-\mathrm{CH}=\mathrm{O} \\
\mathrm{HC}_{2} \mathrm{CHO}\end{array}$ & $\begin{array}{l}\mathrm{H}_{3} \mathrm{COH} \\
\mathrm{H}_{3} \mathrm{CCH}{ }_{2} \mathrm{OH} \\
\mathrm{H}_{3} \mathrm{CSH} \\
\mathrm{H}_{2} \mathrm{C}=\mathrm{C}=0 \\
\left(\mathrm{CH}_{3}\right)_{2} \mathrm{C}=\mathrm{O} \text { ? }\end{array}$ & $\begin{array}{l}\mathrm{HO}-\mathrm{CH}=\mathrm{O} \\
\mathrm{H}_{3} \mathrm{C}-\mathrm{O}-\mathrm{CH}=\mathrm{O} \\
\mathrm{H}_{3} \mathrm{C}-\mathrm{O}-\mathrm{CH}_{3}\end{array}$ & $\begin{array}{l}\mathrm{H}_{2} \mathrm{CNH} \\
\mathrm{H}_{3} \mathrm{CNH}_{2} \\
\mathrm{H}_{2} \mathrm{NCN}^{2}\end{array}$ \\
\hline \multicolumn{4}{|l|}{ Iōes: } \\
\hline $\begin{array}{l}\mathrm{CH}^{+} \\
\mathrm{HN}_{2}^{+} \\
\mathrm{H}_{3} \mathrm{O}^{+}\end{array}$ & $\begin{array}{l}\mathrm{HCS}^{+} \\
\mathrm{SO}^{+} \text {? } \\
\mathrm{HCO}^{+}\end{array}$ & $\begin{array}{l}\mathrm{H}_{2} \mathrm{D}^{+} ? \\
\mathrm{HOCO}\end{array}$ & $\begin{array}{l}\mathrm{HCNH}^{+} \\
\mathrm{HOC}^{+}\end{array}$ \\
\hline \multicolumn{4}{|c|}{ Moléculas ciclicas: } \\
\hline \multicolumn{4}{|l|}{ Radicais: } \\
\hline $\begin{array}{l}\mathrm{CH} \\
\mathrm{OH}\end{array}$ & $\begin{array}{l}\mathrm{C}_{2} \mathrm{H} \\
\stackrel{-\mathrm{C}_{3} \mathrm{H}}{\mathrm{C}} \\
\mathrm{C}_{4} \mathrm{H} \\
\mathrm{C}_{3} \mathrm{H} \\
\mathrm{C}_{6} \mathrm{H}\end{array}$ & $\begin{array}{l}\mathrm{CN}_{2} \\
\mathrm{C}_{1} \mathrm{~N} \\
\mathrm{NS} \\
\mathrm{C}_{2} \mathrm{~S}\end{array}$ & $\begin{array}{l}\mathrm{HCO} \\
\text { NO } \\
\text { SO } \\
\mathrm{H}_{2} \mathrm{CCN}\end{array}$ \\
\hline
\end{tabular}

- Detectadas apenas em invólucros de estrelas

tos de onda. Nesta categoria encontram-se as espécies cíclicas recentemente descobertas $-\mathrm{SiC}_{2}, \mathrm{C}_{3} \mathrm{H}_{2}$ e c- $\mathrm{C}_{3} \mathrm{H}$ - bem como os radicais $1-\mathrm{C}_{3} \mathrm{H}, \mathrm{C}_{4} \mathrm{H}, \mathrm{C}_{5} \mathrm{H}$, $\mathrm{C}_{6} \mathrm{H}, \mathrm{C}_{3} \mathrm{~N}, \mathrm{C}_{2} \mathrm{~S}$ e $\mathrm{CH}_{2} \mathrm{CN}$ que foram identificados à posteriori por espectroscopia laboratorial terrestre. Devemos notar que a espectroscopia laboratorial no espaço pode ser realizada nalguns casos com uma resolução espectral extremamente elevada, como acontece nalgumas nuvens escuras onde a largura da linha espectral é apenas limitada pelo lento movimento térmico a temperaturas abaixo de $-260^{\circ} \mathrm{C}$.

\section{Química complexa associada à Física da formação de nuvens e estrelas}

(Hjalmarson e Friberg, 1988; Friberg e Hjalmarson, 1988)

Nas nuvens cósmicas diluídas, átomos, iðes, moléculas e radicais podem sofrer reacções químicas que nalguns casos dão origem a compostos que sob condiçðes terrestres teriam uma vida curta. Como exemplo, mostramos na Figura 2 o esquema de formação de $\mathrm{H}_{2} \mathrm{O}$ e de $\mathrm{OH}$ por reacções ião-molécula.

O modelo teórico dos processos de formação e destruição que dão origem às moléculas interestelares tornou-se uma parte importante da astroquímica e é extensamente corroborado por medidas laboratoriais de velocidades de reacção relevantes. Uma simulação computacional incluindo 2000 reacçðes acopladas e 200 moléculas e', hoje em dia, um procedimento "trivial". Todo este trabalho conduziu, de facto, a um melhor acordo - embora algumas vezes também a um desacordo crucial - entre abundâncias observadas e previstas. Quando o acordo é satisfatório para as espécies observadas o modelo pode também- ser usado para prever a existência de outras moléculas abundantes que devem, por isso, ser procuradas.

Uma consequência importante deste modelo químico de trabalho é um conhecimento crescente acerca das condiçōes físicas nas nuvens de moléculas. Devemos aqui realçar que as evoluções física e química de uma nuvem não estão separadas mas, pelo contrário, estão ligadas de um modo intrincado. Quando, por exemplo, uma nuvem se contrai adquirindo uma maior densidade nalgumas regiøes localizadas, verificam-se também alteraçð̃es nas velocidades das reacçø̃es químicas devidas à mudança de densidade e temperatura. Por outro lado, as abundâncias moleculares controlarão a contracção da nuvem, através de arrefecimento radiativo, levando à formação de núcleos densos e estrelas. Do mesmo modo, o nível de ionização é crucial uma vez que determina a influência do campo magnético interestelar sobre a evolução da nuvem no sentido da formação de estrelas.

\section{Ambientes diferentes - Alteração da química (Irvine et al., 1987)}

Mostraremos para duas nuvens o modo como a composição química pode depender do meio (cf. Figuras 3 e 4). Vários detalhes e muitos exemplos podem ser encontrados nas referências já mencionadas.

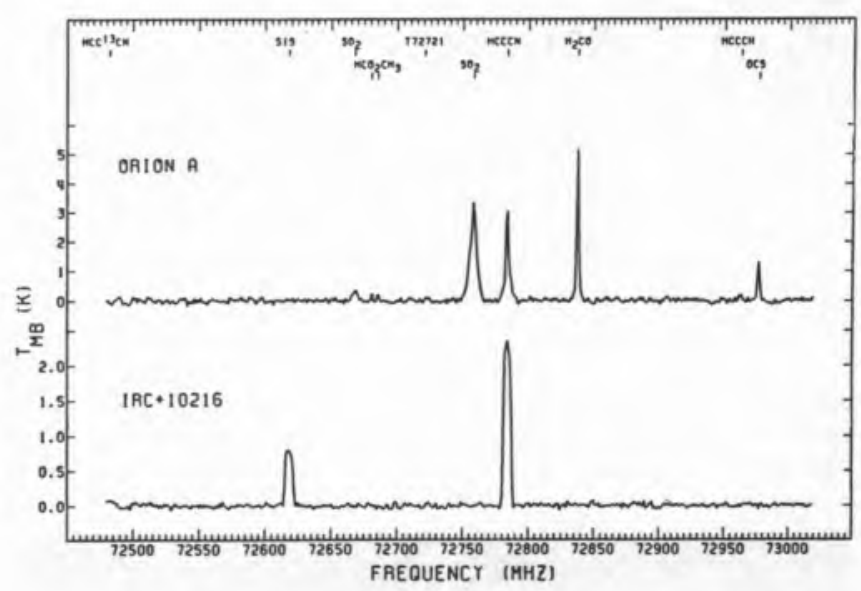

FIGURA 3

Espectros (intensidade de sinal em função da frequência) ilustrativos das diferentes químicas existentes na nuvem geradora de estrelas Orion A (rica em oxigénio) e no invólucro de perda de massa em torno da estrela envelhecida IRC +10216 (rica em carbono)

Algumas estrelas não estão tão nitidamente definidas como o nosso Sol, estando rodeadas de invólucros maciços de gás e poeira que delas fluem (o nosso Sol tem também, no entanto, um vento que é bastante pronunciado para nós, seus vizinhos). A nuvem que circunda a velha e moribunda estrela IRC +10216 , rica em carbono - um dos objectos mais brilhantes no céu infravermelho devido ao seu quente invólucro de poeiras é efectivamente dominada por compostos de carbono. Neste caso, reacções químicas rápidas entre átomos ocorrem na fesca $\left(2500^{\circ} \mathrm{C}\right)$ atmosfera estelar e "quase todo" o O e o N estão na forma de $\mathrm{CO}$ e $\mathrm{HCN}$. O que resta é principalmente $\mathrm{C}$ e $\mathrm{H}$ que produzem $\mathrm{CH}_{4}$, $\mathrm{C}_{2} \mathrm{H}_{2}, \mathrm{C}_{2} \mathrm{H}_{4}, \mathrm{C}_{3} \mathrm{H}_{2}, \mathrm{C}_{2} \mathrm{H}, \mathrm{C}_{3} \mathrm{H}, \mathrm{C}_{4} \mathrm{H}, \mathrm{C}_{5} \mathrm{H}, \mathrm{C}_{6} \mathrm{H}$, $\mathrm{HC}_{3} \mathrm{~N}, \mathrm{HC}_{5} \mathrm{~N}, \mathrm{HC}_{7} \mathrm{~N}, \mathrm{HC}_{9} \mathrm{~N}, \mathrm{HC}_{11} \mathrm{~N}$... Neste meio prevê-se que não existam espécies como $\mathrm{H}_{2} \mathrm{CO}$ e $\mathrm{CH}_{3} \mathrm{OH}$ que se encontram em grandes quantidades em nuvens interestelares frias.

Na nuvem de moléculas de Orion, por detrás da Orion gigante (Figura 5) o meio contém mais $\mathrm{O}$ e a temperatura é bastante mais baixa $\left(-250^{\circ} \mathrm{C}\right.$ a $\left.-50^{\circ} \mathrm{C}\right)$. 


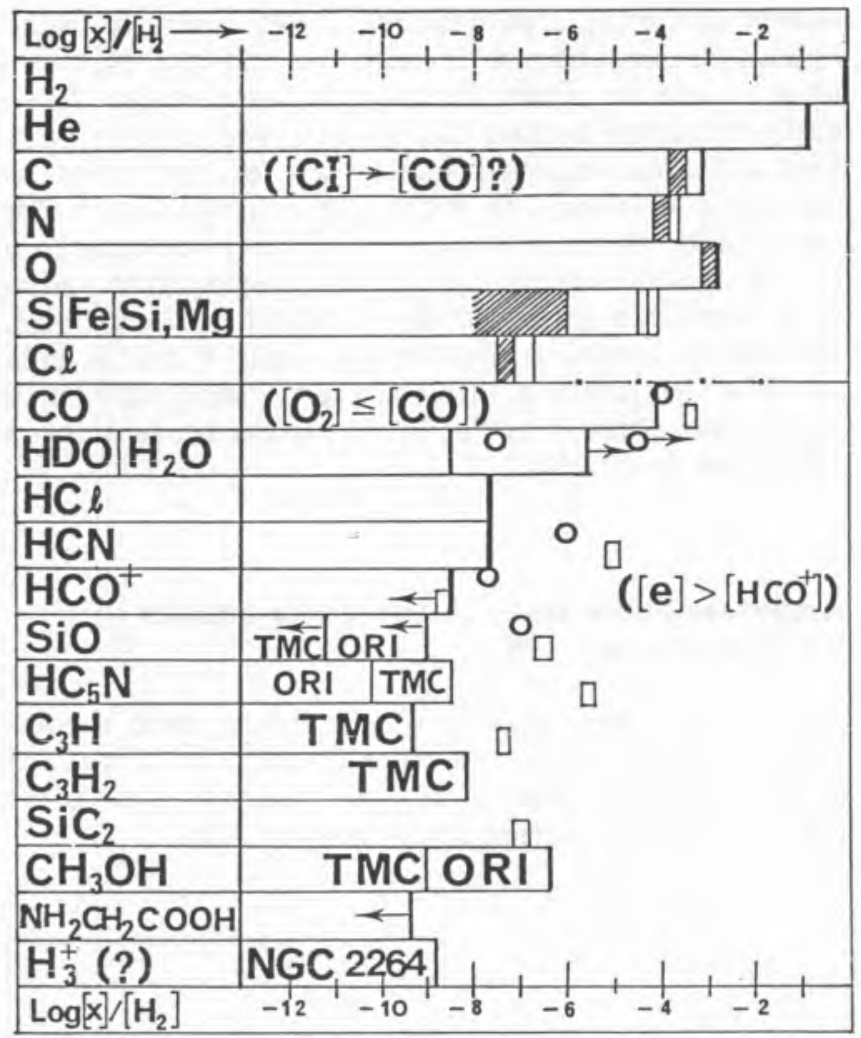

O Planalto de orion (fluxo rico em 0 )

(] IRC+10216 (fluxo rico em C)

־ iinite superior e limite inferior

abundáncía elementar esgotada

FIGURA 4

Abundância dos elementos e concentraçōes moleculares seleccionadas existentes em Orion A (nuvem ambiental quente bem como fluxo rico em O), em IRC+10216 (fluxo rico em C) e na fria nuvem escura TMC-1

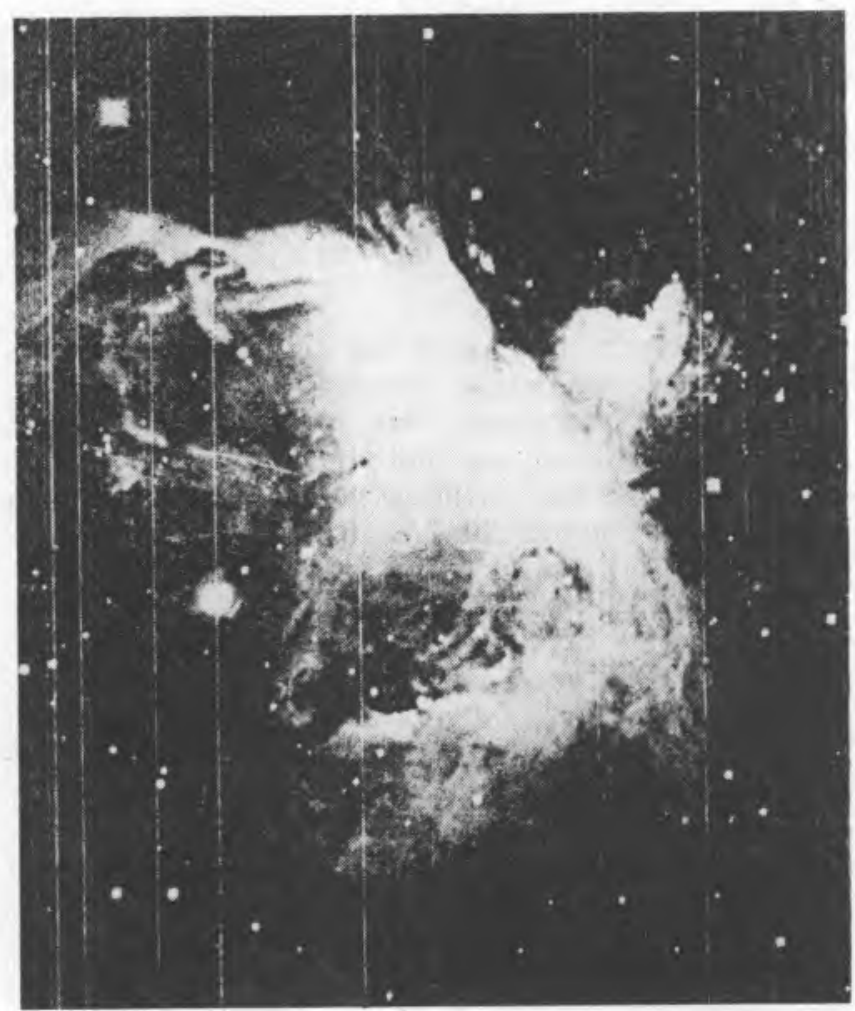

FIGURA 5

Nebulosa de Orion
Aí a ,química é dominada por reações ião molécula (cf. Figura 2) e foram identificados, por exemplo, $\mathrm{H}_{2} \mathrm{O}, \mathrm{H}_{2} \mathrm{CO}, \mathrm{CH}_{3} \mathrm{OH},\left(\mathrm{CH}_{3}\right)_{2} \mathrm{O}$ (éter dimetílico) $\mathrm{HCOOH}$ (ácido fórmico - o ácido irritante de algumas formigas!) e $\mathrm{HCOOCH}_{3}$ (formato de metilo). Os isómeros de éter dimetílico e formato de metilo, $\mathrm{CH}_{3} \mathrm{CH}_{2} \mathrm{OH}$ (etanol) e $\mathrm{CH}_{3} \mathrm{COOH}$ (ácido acético) respectivamente, não foram, no entanto, ainda descobertos. Isto demonstra uma selectividade química que ainda não foi esclarecida de forma conveniente pelo modelo teórico.

Uma baixa abundância pode, contudo, não ser a razão pela qual certas moléculas escapam à detecção. $\mathrm{O}$ verdadeiro motivo tem a ver, frequentemente, com o facto de espécies complexas mais pesadas poderem emitir sinais a tantos comprimentos de onda diferentes que conduzem a um sinal muito fraco em cada linha espectral possível. O formato de metilo, com as suas 10000 transiçøes permitidas na região das ondas de rádio é, com efeito, um bom exemplo desta diluição da força do sinal, embora se tenha verificado que a sua concentração é suficientemente grande para poder ser detectado. A ausência de evidência não deve ser interpretada como evidência para a ausência de espécies tais como $\mathrm{CH}_{3} \mathrm{COOH}$ ou, pela mesma razão, de $\mathrm{NH}_{2} \mathrm{CH}_{2} \mathrm{COOH}$ (ácido aminoacético). Apesar dos limites de intensidade poderem ser bastąnte baixos, os limites de abundância não o são (cf. Figura 4)!! Isto pode aplicar-se ainda melhor a compostos em anel que são bastante abundantes no nosso próprio ambiente. No gás interestelar (circumestelar) apenas se identificaram até agora $\mathrm{SiC}_{2}, \mathrm{C}_{3} \mathrm{H}_{2}$ e $\mathrm{C}_{3} \mathrm{H}$ cíclico. Estes compostos em anel, de tamanho mínimo, constituem provavelmente tão só a ponta de um "iceberg" de moléculas cíclicas cósmicas, mais ou menos complexas (??), dado que $\mathrm{C}_{3} \mathrm{H}_{2}$ é, de facto, uma espécie muito abundante.

Enigmáticos (misteriosos?) grãos de poeira

(Tielens e Allamandola, 1987)

O hidrogénio molecular desempenha um papel crucial na formação de compostos químicos mais complicados embora não se possa obter facilmente em fase gasosa dada a necessidade dos átomos de $\mathrm{H}$ serem adsorvidos à superfície dos grãos. A composição química das partículas de poeira não é muito bem conhecida sabendo-se, no entanto, que elas contêm elementos mais pesados como $\mathrm{C}, \mathrm{O}, \mathrm{Si}, \mathrm{Mg}$ e $\mathrm{F}$, uma vez que estes "metais" estão ausentes da fase gasosa e são produzidos sobretudo como condensados durante a fase de perda de massa (gás/fluxo de poeira) das estrelas moribundas.

Os grãos de poeira estão bem misturados com os gases nas nuvens cósmicas e fazem sobressair as mais próximas como zonas escuras no céu (aliás, como foi observado há 200 anos por Herschel), uma vez que absorvem quase completamente a luz de fundo das estrelas. Estas poeiras protegem com eficiência os interiores das nuvens da luz UV intensa das estrelas recentemente nascidas que, de outro modo, destruiria a maior parte das moléculas em formação.

Por outro lado, observaçð̄es recentes no domínio do infravermelho e espectroscopia laboratorial sugerem que grãos de poeira orgânica podem também existir, sendo constituídos por grandes moléculas de Hidrocarbonetos Aromáticos Policíclicos, PAH:s (cf. Allamandola et al., 1987 e Léger et al., 1987). 


\section{Sondando o interior das nuvens de moléculas} (Hjalmarson e Friberg, 1988; Friberg e Ajalmarson, 1988)

Apesar do $\mathrm{H}_{2}$ ser de longe a molécula mais abundante, não nos esclarece directamente sobre a sua existência na escuridão poeirenta das maciças e frescas nuvens de moléculas. Sendo uma molécula simétrica não pode emitir radiação às baixas temperaturas das nuvens embora, quando excitada por choque a temperaturas mais altas, possa emitir linhas vibracionais que têm sido de facto observadas.

Há, no entanto, muitas outras moléculas que devido a uma distribuição de carga assimétrica servem como "antenas radiantes microscópicas". Quando uma molécula deste tipo altera o seu movimento rotacional (no sentido "clássico"), é emitida um absorvida energia sob a forma de fotőes de "comprimentos de onda" específicos (no sentido "mecânico-quântico"). Estas moléculas vestigiais emitirão radiação detectável apenas quando suficientemente excitadas para estados de energia superiores através de colisð̃es com $\mathrm{H}_{2}$ cuja velocidade tem que ser maior que a probabilidade de emissão espontânea ("'mecânica quântica") para a transição observada. A partir de um modelo de excitação molecular e transferência radiativa nas nuvens, podem traçar-se as distribuiçð̃es de densidade, massa, temperatura e velocidade, i) com pormenor assinalável em nuvens de moléculas na Via Láctea e, ii) a uma escala maior, nas galáxias próximas. Este conhecimento é importante para a compreensão dos processos de formação de estrelas e nuvens e trás alguma informação sobre morfologia, cinemática e evolução de galáxias, quando em conjunção com um modelo teórico.

O traçado de mapas de interiores de nuvens tem fornecido não só informação sobre as condiçð̄es iniciais necessárias à formação de estrelas como tem também - e bastante inesperadamente para os teóricos da formação de estrelas - tornado clara a existência de uma fase importante de perda de massa durante os primeiros tempos da evolução estelar. Observam-se frequentemente bandas espectrais azuis e deslocadas para o vermelho em transiçð̃es do monóxido de carbono, indicando muitas vezes fluxos bi-polares (bi-direccionais). Talvez se devesse completar esta secção fazendo notar que nem a molécula vestigial mais abundante, o $\mathrm{CO}$, contribui em mais de $0.1 \%$ para as massas de nuvem observadas (cf. mais uma vez a Figura 4).

\section{A vida e o grande ciclo do nascimento, evolução e morte estelar}

(Ponnamperuma, 1983; Kwok e Pottasch, 1987)

Uma estrela vulgar como o Sol é estável desde que possa libertar energia, o que ocorre durante cerca de $5 \times 10^{9}$ anos. Quando os elementos leves tiverem sido consumidos a estrela começa a sua agonia. Uma estrela pesada, com por exemplo, $30 \mathrm{M}_{\circ}$, explodirá então dando origem a uma supernova. Em poucos dias tornar-se-á tão brilhante como todas as estrelas na galáxia juntas. Numa estrela pesada deste tipo a energia de fusão dura apenas $10^{6}$ anos. Estrelas de menor massa, como o Sol, expelirão a sua matéria transformada dum modo mais calmo, desenvolvendo-se à sua volta nuvens em expansão de gás e poeiras que podem ser observadas através da sua radiação molecular e infravermelha - tal como no caso da IRC + 10216
Através das reacçōes de fusão nas estrelas e da expulsão de massa que decorre à medida que vão evelhecendo, a concentração de elementos mais pesados - "metais" - aumenta continuamente nas nuvens interestelares. Algures, nalgum momento deste gigantesco ciclo de gás, a concentração de metais foi suficient elevada para acomodar o Sol com os seus companheiros, os planetas, alguns dos quais muito ricos em metais. Num deles, Tellus (Terra), um insignificante corpo pesado, apareceram as condiçð̄es necessárias à vida.

Embora existam no espaço interestelar moléculas orgânicas tão diferentes seria presunção - e, pelo menos, em parte um erro - dizer-se que isto está relacionado com a origem da vida no nosso planeta. As astromoléculas existentes demonstram claramente, todavia, a magnífica capacidade do carbono para formar cadeias estáveis em ambientes não hostis - uma característica que foi, de certo, importante para a origem da vida. Poderá também acontecer que algumas moléculas críticas - necessárias como parceiros reaccionais ou catalisadores - tenham chegado à vida terrestre formando lagos de lama após terem sido sintetisadas em nuvens de gás interestelar ou em cometas.

\section{Agradecimentos}

Gostaria de agradecer a colegas espalhados por muitos países, em especial a Olof Rydbeck, meu professor no observatório espacial de Onsala e a Bill Irvine, meu amigo da Universidade de Massachusetts, pela colaboração e discussões estimulantes; ao Conselho Sueco de Investigação de Ciências Naturais (NFR), pelo forte apoio; à Fundação Portuguesa de Ciência, por financiar a minha estada recente no Porto $e$, por último, aos meus colegas em Coimbra, Gaia e Porto pelos seus sonhos inspiradores e amizade.

\section{Referências}

- S. Wienberg, "Os três primeiros minutos", Gradiva, 1987. - Nature, 324, 6096 (1988) (número sobre o Cometa Halley)

- L. Blitz, "Gigant molecular cloud complexes in the Galaxy", Scientific American, Abril, 1982.

- A.. Hjalmarson, P. Friberg, "Radio and (sub)millimeter observations of the initial conditions for star formation in formation and evolution of low mass stars", eds. Dupree e Lago, Reidel, 1988 (Curso avançado da NATO, Viana do Castelo, Portugal, Outubro 1987).

- D.J. Holenbach, A. Thronson, Jr., (eds.), "Interstellar processes", Reidel, 1987.

- D.C. Black, M.S. Matthews (eds.) "Protostars and planets, II", p. $579,1987$.

- W.M. Irvine, P.F. Goldsmith, A.. Hjalmarson, em "Interstellar processes", p. 561 .

- A.G.G.M. Tielens, L.J. Allamandola, em "Interstellar porcesses", p. 397.

- L.J. Allamandola, A.G.G.M., J.R. Baker, em "Interstellar processes", p. 561 .

- A. Léger, L. d'Hendrecourt, N. Boccara (eds.) "Polycyclic aromatic hydrocabons and Astrophysics", Reidel, 1987.

- P. Friberg, Ä. Ajalmarson, "Molecular clouds in the Milky Way" a ser publicado no Molecular Astrophysics, ed. T. Hartquist, Cambridge, University Press.

- C. Ponnamperuma (ed.) "Cosmochemistry and the origin of life", Reidel, 1983.

- S. Kwok, R.S. Pottasch (eds.) "Late stages of stellar evolution", Reidel, 1987. 


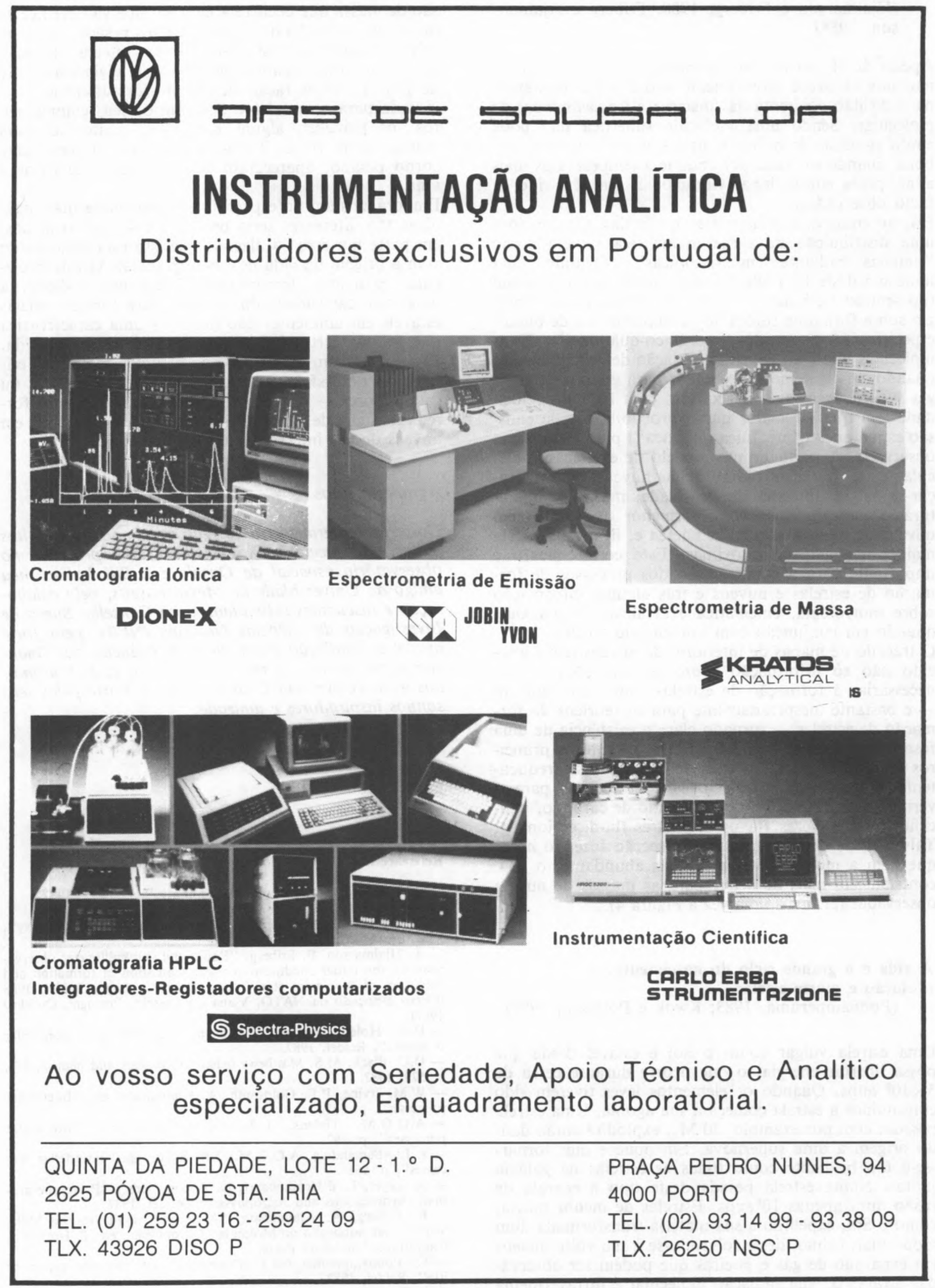

